\title{
Homicídios e vulnerabilidade social
}

\author{
Homicides and social vulnerability
}

\author{
Ricardo Tavares ${ }^{1}$ \\ Valeria Dutra Batista Catalan ${ }^{2}$ \\ Pedro Machado de Melo Romano ${ }^{2}$ \\ Elza Machado Melo ${ }^{2}$
}

${ }^{1}$ Departamento de Estatística, Instituto de Ciências Exatas e Biológicas, Universidade Federal de Ouro Preto. Campus Universitário, Morro do Cruzeiro. 35400-000 Ouro Preto MG Brasil. tavares@iceb.ufop.br ${ }^{2}$ Núcleo de Promoção de Saúde e Paz, Departamento de Medicina Preventiva e Social, Faculdade de Medicina, Universidade Federal de Minas Gerais. Belo Horizonte MG Brasil.
Abstract The goal of this study was to analyze the spatial distribution of homicide rates $(H)$ according to the social vulnerability index (SVI) and the quality of urban life index (QUL) in Betim, State of Minas Gerais, from 2006 to 2011. Descriptive analysis was performed using Moran's spatial correlation analysis, and the H, SVI and QUL spatial analyses. During this period there were 1,383 deaths, mostly of males (91.9\%), aged 15-24 years (46.9\%), brown/black (76.9\%), with secondary education (51.1\%), and single (83.9\%). No spatial autocorrelation was revealed, indicating that the distribution of homicide rates is random; the same occurred with the SVI and the QUL index. Taken together, however, the H, SVI and QUL index overlapped, which was analyzed using different theories of crime, such as those addressing socioeconomic issues, arms of drugs dealing and Durkheim's and Habermas' theories, namely anomie and colonization of the lifeworld. Conclusion: social vulnerability and homicide are associated from both empirical and theoretical perspectives. Key words Violence, Homicide, Vulnerability
Resumo O objetivo deste estudo foi analisar a distribuição espacial das taxas de homicídios $(H)$ segundo os indices de vulnerabilidade social (IVS) $e$ de qualidade de vida urbana (IQVU), em Betim/MG, de 2006 a 2011. Foram feitas análise descritiva, análise de correlação espacial utilizando o indice de Moran e análise espacial de H, IVS e IQVU. Ocorreram no período, 1.383 óbitos, com predominio de homens (91,9\%), de 15 a 24 anos (46,9\%), pardos/pretos $(76,9 \%)$, com ensino médio $(51,1 \%)$ e solteiros $(83,9 \%)$. Não se verificou autocorrelação espacial, indicando que a distribuição das taxas de homicídio é aleatória, o mesmo ocorrendo com o IVS e com o IQVU. Em conjunto, no entanto, houve sobreposição de H, IVS, $I Q V$, o que foi analisado à luz de diferentes teorias explicativas do crime, desde as que abordam a desigualdade social, passando pelas que pautam o tráfico de armas e drogas até chegar às teorias de Durkheim e Habermas, respectivamente, anomia e colonização do mundo da vida. Conclusão: tanto do ponto de vista empírico como teórico, vulnerabilidade social e homicídio se mostram associados. Palavras-chave Violência, Homicídio, Vulnerabilidade social 


\section{Introdução}

Por suas repercussões em todos os âmbitos da vida dos indivíduos, grupos e nações, assim como pela magnitude e fortes impactos físicos e psicológicos, a violência constitui um problema e grande desafio para o setor saúde ${ }^{1}$. O homicídio é a expressão máxima da violência interpessoal e sua irracionalidade bem se expressa por sua contraditória condição de ser a principal causa prevenível de morte, a interromper a vida de milhares de cidadãos em todo o mundo ${ }^{2}$.

Países da África e da América Latina, com exceção de dois países - Coréia e Papua Nova Guiné - dividem entre si as primeiras 60 maiores taxas de homicídios, com destaque para Honduras, El Salvador, Costa do Marfim, Jamaica, Venezuela, Belize e Guatemala, que ocupam o topo da lista, com valores maiores de 41 por 100.000 habitantes. Por outro lado, não deixa de ser alentador - e significativo para as possibilidades de prevenção - o fato de que 21 países do mundo têm taxas menores do que 1 morte por 100.000 e 60 deles têm taxa menores 1,9 homicídios por 100.000 habitantes, entre esses o Canadá, único país das Américas incluído nessa lista ${ }^{3}$. O Brasil tem a $26^{\mathrm{a}}$ maior taxa de mortalidade por homicídio no mundo, estando à sua frente, nesse quesito, apenas países da África e da América Latina. Aqui no nosso país, no período de 1991 a 2011, 922.559 pessoas foram a óbito por homicídios, tendo sido de 27,4 mortes/100.000 habitantes a taxa de mortalidade, em 2011 ${ }^{4}$. É marcante a diferença entre os sexos, com taxas de mortalidade entre os homens que são 10 vezes em média maiores dos que as taxas entre as mulheres, chegando a ser maior 12 vezes mais, em alguns momentos.

O homicídio tem profundo significado social, não só porque interrompe a vida, direito mais elementar de todo cidadão, mas também por ser um reflexo dos problemas existentes na sociedade, relacionados tanto a variáveis macrossociais, como desigualdade, impunidade, corrupção, presença do crime organizado e outros, como a aspectos próprios de espaços privados de convivência interpessoal, especificamente, a violência doméstica $^{5}$ - não por acaso, as maiores taxas de homicídios ocorrem em países de baixo desenvolvimento e eles são muito mais frequentes nos países onde há desigualdades sociais ${ }^{3}$. Constitui, pois, questão que interessa ao Direito, cujas premissas ofende radicalmente, remetendo, portanto à criminologia, e à Saúde Pública, por sua vinculação com a estrutura social desigual e excludente ${ }^{6}$. É nessa perspectiva que se insere o pre- sente artigo, que tem por objetivo estudar a associação entre homicídios e vulnerabilidade, no período de 2006 a 2011, no Município de Betim, Minas Gerais, a partir de análise espacial, método também utilizado em outros estudos, referentes, por exemplo, à associação de homicídio com tráfico de drogas ${ }^{7}$; à interiorização da violência ${ }^{8}$ e ao modo de organização do espaço urbano9.

Betim, Município da Região Metropolitana de Belo Horizonte/MG, tem características de cidade de médio porte, é um dos importantes polos industriais de Minas Gerais e teve crescimento desordenado a partir da implantação de duas das suas principais empresas, a Fiat automóveis e a Refinaria Gabriel Passos. A população é de 383.571 habitantes, o Índice de Desenvolvimento Humano Municipal de 0,749 e a renda per capita de R\$757,00. Grandes indústrias ao lado de inúmeros aglomerados urbanos de precárias condições de vida expressam a concentração de renda e a acentuada desigualdade social do Município ${ }^{10}$.

\section{Metodologia}

Trata-se de um estudo transversal - epidemiológico e espacial - da mortalidade por homicídios no município de Betim, Minas Gerais, no período de 2006 a 2011. Para realização deste estudo, foram utilizados dados de fonte secundária, extraídos das declarações de óbitos (DO), lançadas no sistema de informação de mortalidade (SIM) local. Foram selecionados os óbitos de residentes no município de Betim entre 2006 e 2011, classificados como homicídios (X85 a Y09), segundo a Classificação Internacional de Doenças, em sua $10^{\mathrm{a}}$ atualização (CID 10). Com relação aos dados da população, foram utilizados os do Censo Demográfico de $2010^{7}$, para os anos de 2010 e 2011, e para os demais, 2006 a 2009, os das estimativas populacionais do Instituto Brasileiro de Geografia e Estatística (IBGE). Os dados extraídos do banco de registros de mortalidade local em Excel foram transportados para o programa Statistical Package for Social Sciences - SPSS, versão 19.

A análise espacial foi feita com base em Unidades de Planejamento (UP), definidas no município como unidades geográficas. As UPs têm características demográficas semelhantes e são, em termos populacionais, maiores que os setores censitários. O município possui 133 UPs.

A taxa de mortalidade por homicídios, no ano, para cada UP, foi obtida dividindo o número de homicídios no ano pela população nesse ano, multiplicada por 100 mil. Como as populações 
por UP estavam disponíveis apenas para o ano de 2010, este foi usado para calcular os pesos de cada UP e de forma proporcional distribuir a população total de Betim nos outros anos entre as UPs consideradas. As taxas de homicídios de cada UP utilizadas na análise espacial referem-se ao período todo, de 2006 a 2011, e foram calculadas somando-se o total dos homicídios nos 6 anos e dividindo-se este número pela soma da população, também nos seis anos, multiplicando-se por $100 \mathrm{mil}$.

As UPs com população inferior a 60 habitantes (27 UPs) foram desconsideradas, pois se o número de pessoas expostas é pequeno, qualquer pequena mudança no número de eventos, mesmo que devido ao mero acaso, provocará grandes variações no valor da taxa ${ }^{7}$.

Como medida de vulnerabilidade social a ser relacionada com a distribuição das taxas de homicídios, foram utilizados, neste estudo, o Índice de Qualidade de Vida Urbana (IQVU) e o Índice de Vulnerabilidade Social (IVS) das 106 UPs participantes do estudo. Esses índices foram elaborados por Nahas ${ }^{11}$, sendo que para o IQVU, foram utilizados 15 indicadores referentes às variáveis educação, esportes, habitação, saúde e segurança. Para o IVS, foram utilizados 11 indicadores de acesso social, a saber: moradia (Dimensão Ambiental Urbana); renda (Dimensão Econômica); saúde e segurança (Dimensão Segurança de Sobrevivência) e escolaridade (Dimensão Cultural).

Foi feita análise descritiva, com distribuição de frequência e análise univariada dos homicídios segundo variáveis sociodemográficas (sexo, idade, raça/cor, estado civil, renda, escolaridade), características do homicídio e do local de ocorrência. Não foi possível realizar a análise de série histórica dos indicadores de mortalidade por homicídio, em virtude da redução da população verificada com o recenseamento demográfico de 2010 do $\mathrm{IBGE}^{10}$, e consequente superestimação da população nos anos intercensitários.

Foi realizada também análise de dependência espacial das taxas de homicídios por meio da verificação de autocorrelação espacial, usando o Índice de Moran ${ }^{12,13}$. Os valores desse índice variam de -1 a 1 , sendo que valores positivos indicam autocorrelação espacial positiva, ou seja, os valores das variáveis de uma área tendem a ser semelhantes aos das áreas vizinhas; valores negativos indicam o contrário ${ }^{14}$. Os testes de autocorrelação espacial foram realizados usando o pacote spdep do ambiente computacional R. Por fim, foi realizada análise comparativa da distribuição espacial das taxas de homicídios nas UPs, a partir do local de residência das vítimas de homicídios (e não por local de ocorrência), com a distribuição espacial dos índices de vulnerabilidade social (IVS) e de qualidade de vida urbana (IQVU). Como separatrizes, foram utilizados os percentis 10 (P10), 30 (P30), 70 (P70) e 90 (P90), pois eles permitem mostrar um detalhamento maior nas caudas (ou nos extremos) da distribuição da variável estudada. A TXHOM, o IVS e o IQVU de percentil até 30 (P30) foram considerados baixos; de 30 (P30) até 70 (P70) médios; e, por fim, igual ou superior a 70 (P70), altos. Destaca-se ainda que, quanto maior o percentil do IVS e do IQVU, maior será, respectivamente, a desigualdade social e a qualidade de vida, para a UP correspondente.

Para analisar a sobreposição de TXHOM, IVS e IQVU, foi criada uma variável denominada Variações, cujas categorias são: variação grande (VarG); variação pequena (VarP) e variação nula (Var0), cujas definições são mostradas no Quadro 1.

A distribuição das taxas de homicídio, do IVS e do IQVU, segundo as UPs, assim como sua comparação, foi apresentada nos mapas obtidos por meio do pacote Maptools do ambiente computacional $\mathrm{R}$, software estatístico livre para análise e manipulação de dados, com testes paramétricos e não paramétricos e análise espacial.

Devido às insuficiências de registro de dados primários nas declarações de óbito, dos 1.383 óbitos por homicídios ocorridos no período analisado, 47 não foram georreferenciados $(3,4 \%)$. Nos casos em que foi registrado na DO o nome da rua, sem o número da residência, optou-se por marcar o ponto médio do logradouro para viabilizar o georreferenciamento.

Quadro 1. Variações e suas categorias utilizadas na análise de sobreposição de TXHOM, IVS e IQVU.

\begin{tabular}{|l|l|l|}
\hline Variações & TXHOM & IVS ou IQVU \\
\hline VarG & $\begin{array}{l}\text { Baixo } \\
\text { Alto }\end{array}$ & $\begin{array}{l}\text { Alto } \\
\text { Baixo }\end{array}$ \\
\hline VarP & $\begin{array}{l}\text { Baixo } \\
\text { Médio } \\
\text { Médio } \\
\text { Alto }\end{array}$ & $\begin{array}{l}\text { Médio } \\
\text { Baixo } \\
\text { Alto } \\
\text { Médio }\end{array}$ \\
\hline Var0 & $\begin{array}{l}\text { Baixo } \\
\text { Médio } \\
\text { Alto }\end{array}$ & $\begin{array}{l}\text { Baixo } \\
\text { Médio } \\
\text { Alto }\end{array}$ \\
\hline
\end{tabular}


Este estudo faz parte de uma pesquisa maior intitulada Saúde e Violência: Subsídios para a Formulação de Políticas Públicas de Promoção de Saúde e Prevenção da Violência, aprovada pelo Comitê de Ética da Universidade Federal de Minas Gerais.

\section{Resultados}

No período estudado foram registradas no SIM, 1.383 vítimas fatais de agressão, sendo esta a segunda causa de morte entre todas as causas e a primeira causa externa de mortalidade, em Betim. Até o ano de 2008, essa era a primeira causa de óbito no Município.

Houve, no período, redução de 7\% no número de homicídios, a taxa de mortalidade passando de 59,2 por 100 mil em 2006, para 58,7 por 100 mil em 2011. No entanto, Betim se mantém entre os municípios mais violentos do Brasil, cuja taxa de mortalidade por agressão, em 2011, foi de 27,1 por 100 mil habitantes. Os homicídios foram responsáveis, em 2006 , por $66,4 \%$ do total de mortes por causas externas e, em 2011, por $60,0 \%$ delas.

Sobre o perfil das vítimas fatais de homicídios, observou-se o acometimento prioritário de pessoas jovens de 15 a 24 anos (46,9\%), do sexo masculino $(91,9 \%)$, pardos e pretos $(76,9 \%)$, solteiros $(83,9 \%)$, com nível médio de escolaridade (51,1\%), vítimas de arma de fogo $(89,6 \%)$, tendo o óbito ocorrido em vias públicas em $47,9 \%$ dos casos. Em todo o período, os percentuais de homicídios foram mais elevados na faixa etária de 15 a 24 anos, variando de $47,3 \%$ no primeiro ano a 50,2\% no último. O número de homicídios por arma de fogo predomina amplamente e explica o fato de a maior parte dos óbitos ter ocorrido em vias públicas, sem que houvesse tempo e recursos suficientes para socorro. (Tabela 1).

O valor do Índice de Moran, calculado para verificar a existência de autocorrelação espacial das taxas de homicídios, ficou próximo de zero (-0.03735529), indicando que não há dependência espacial e que as taxas de homicídios no município se distribuem aleatoriamente. O mesmo ocorreu para o IVS e para o IQVU. Isso foi confirmado pelos testes de autocorrelação espacial.

A Figura 1 apresenta os mapas com a malha geográfica do município de Betim, com as taxas de homicídios por UP, os índices de vulnerabilidade social e os de qualidade de vida urbana. O primeiro mapa, com a malha geográfica, inclui todas as 133 Unidades de Planejamento (UP); os demais mapas apresentam os dados concen-
Tabela 1. Distribuição dos homicídios para as variáveis estudadas, Betim, 2006 a 2011.

\begin{tabular}{|c|c|c|}
\hline Variáveis & Frequência & $\%$ \\
\hline \multicolumn{3}{|l|}{ Sexo } \\
\hline Masculino (R) & 1271 & 91,9 \\
\hline Feminino & 112 & 8,1 \\
\hline \multicolumn{3}{|l|}{ Faixa etária } \\
\hline 1 a 14 anos & 18 & 1,2 \\
\hline 15 a $24 \operatorname{anos}(\mathrm{R})$ & 649 & 46,9 \\
\hline 25 a 29 anos & 269 & 19,5 \\
\hline 30 a 59 anos & 420 & 30,4 \\
\hline 60 anos e mais & 27 & 2,0 \\
\hline \multicolumn{3}{|l|}{ Raça ou cor } \\
\hline Branca & 313 & 22,6 \\
\hline Preta ou Parda (R) & 1063 & 76,9 \\
\hline Amarela & 2 & 0,1 \\
\hline Indígena & 1 & 0,1 \\
\hline Ignorado & 4 & 0,3 \\
\hline \multicolumn{3}{|l|}{ Estado Civil } \\
\hline Solteiro (R) & 1160 & 83,9 \\
\hline Casado & 144 & 10,4 \\
\hline Viúvo & 12 & 0,9 \\
\hline Separado judicialmente & 48 & 3,5 \\
\hline União estável & 11 & 0,8 \\
\hline Ignorado & 8 & 0,4 \\
\hline \multicolumn{3}{|l|}{ Escolaridade } \\
\hline Fundamental (1 $1^{\mathrm{a}}$ a $4^{\mathrm{a}}$ séries) (R) & 25 & 1,8 \\
\hline Fundamental ( $5^{\mathrm{a}}$ a $8^{\mathrm{a}}$ séries $)$ & 148 & 10,7 \\
\hline Médio & 707 & 51,1 \\
\hline Superior incompleto & 438 & 31,7 \\
\hline Superior completo & 38 & 2,7 \\
\hline Ignorado & 27 & 2,0 \\
\hline \multicolumn{3}{|l|}{ Causas básicas } \\
\hline Arma de fogo (R) & 1239 & 89,6 \\
\hline Arma branca & 96 & 6,9 \\
\hline Afogamento & 1 & 0,1 \\
\hline Enforcamento & 9 & 0,7 \\
\hline Outras & 38 & 2,7 \\
\hline \multicolumn{3}{|l|}{ Local de ocorrência } \\
\hline Estabelecimentos de saúde (R) & 397 & 28,7 \\
\hline Domicílio & 126 & 9,1 \\
\hline Via pública & 663 & 47,9 \\
\hline Outros & 195 & 14,1 \\
\hline Ignorado & 2 & 0,1 \\
\hline
\end{tabular}

Fonte: SIM/SMS - 2006 a 2011.

trados nas 106 UPs, incluídas no estudo. Verificou-se uma predominância de áreas com taxas de mortalidade por homicídio que variam de 17,22 a 58,08 mortes por 100 mil habitantes. Regiões dispersas no município têm áreas cujas taxas são muito elevadas e ultrapassam 88 mortes por 100 mil habitantes. 
(a)

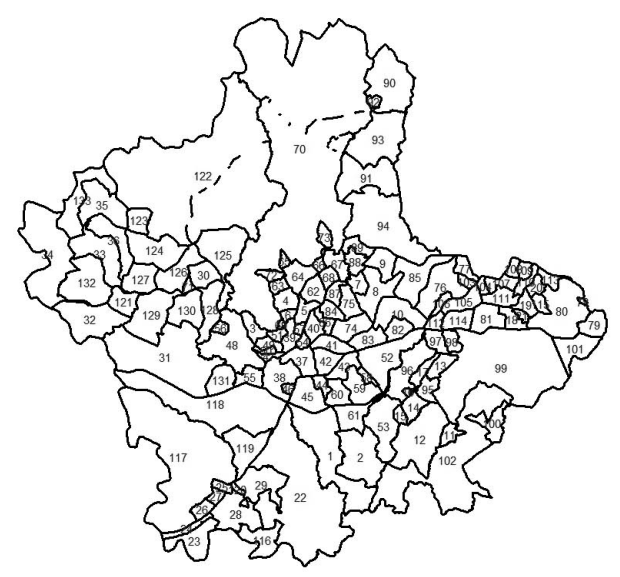

(c)

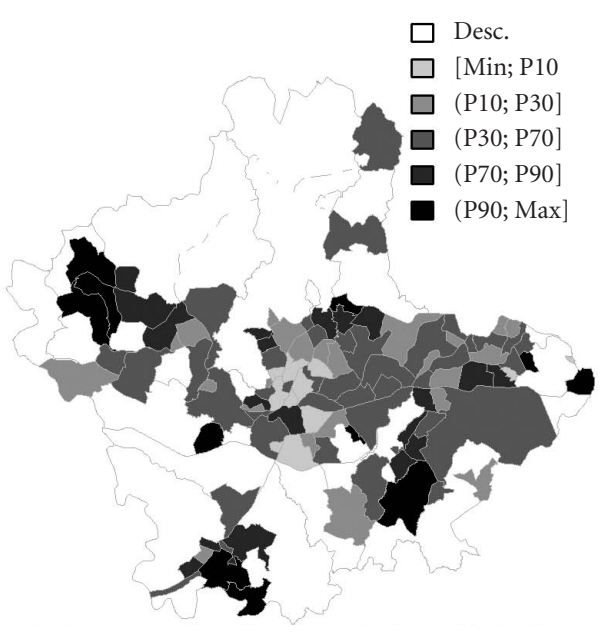

(b)

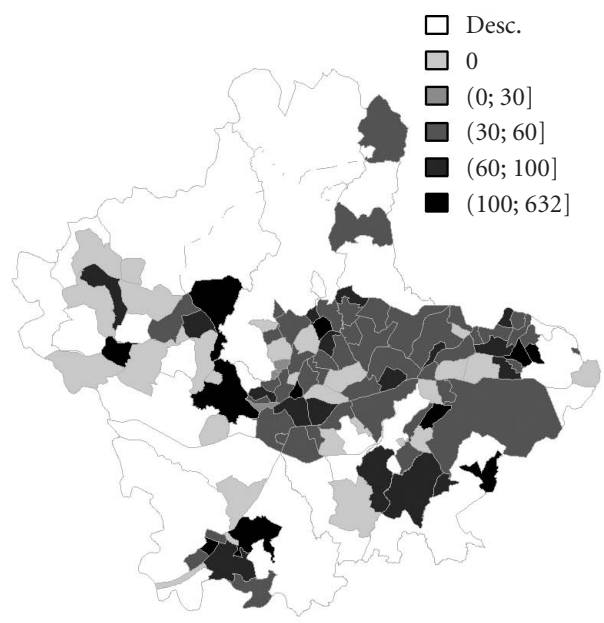

(d)

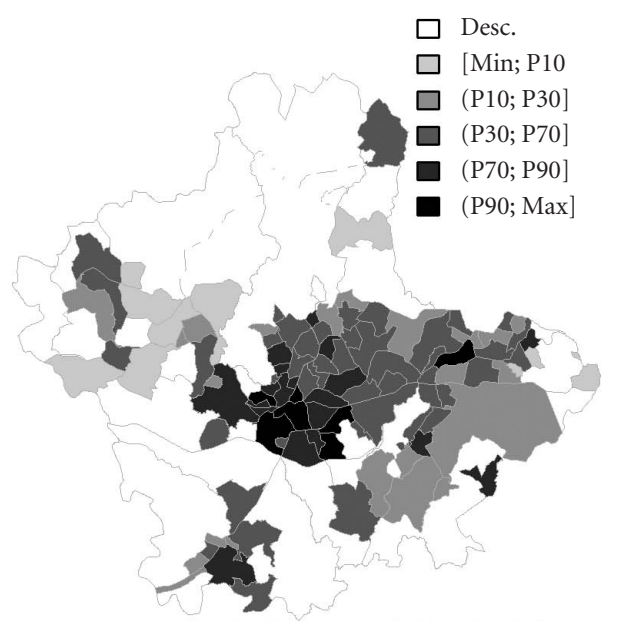

Figura 1. Distribuição espacial das Unidades de Planejamento, das taxas de homicídios, do Índice de vulnerabilidade social e do Índice de qualidade de vida urbana, Betim, 2006-2011.

Do mesmo modo, destacam-se as áreas com média e elevada vulnerabilidade social como sendo as maiores do estudo, caracterizando dessa forma, em razão da dispersão encontrada, uma população socialmente vulnerável. O último mapa representa os índices de maior qualidade de vida urbana, em áreas concentradas na região central do município.

Por meio da Figura 2, observa-se a maior ocorrência de homicídios em áreas de maior vulnerabilidade social e de menor qualidade de vida urbana. No primeiro mapa, há predominância clara das áreas onde ocorre coerência entre taxa de homicídio e índice de vulnerabilidade social, ou seja, altas taxas de homicídio ocorrem em áreas com elevada vulnerabilidade social, baixas taxas de homicídios em áreas de baixa vulnerabilidade social e taxas médias nas áreas de média vulnerabilidade. Tais áreas apresentam variação zero ou nula (Var0).

Ainda na Figura 2, o segundo mapa, com o cruzamento da taxa de homicídio por UP com o índice de qualidade de vida urbana, apresenta resultados inversos e análogos, sendo predominantes as áreas com altas taxas de homicídio e baixo IQVU, baixas taxas e elevado IQVU (variação grande - VarG), assim como médias taxas e médio IQVU (Var0 e VarP). 
(a)

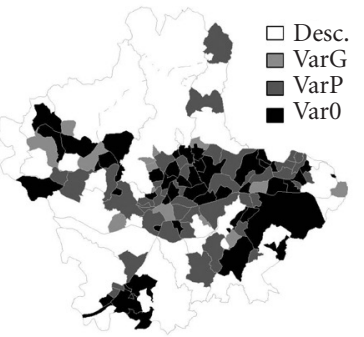

(b)

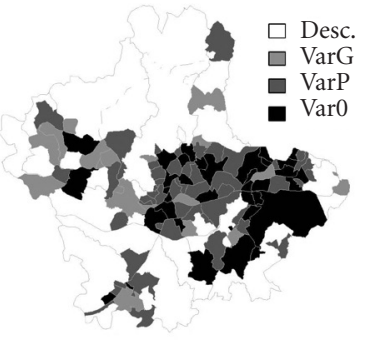

Figura 2. Sobreposição espacial entre taxas de homicídios e Índice de Vulnerabilidade Social e entre taxas de homicídios e Índice de Qualidade e Vida Urbana, Betim, 2006-2011.

\section{Discussão}

O artigo mostra que a distribuição dos homicídios, em Betim, não é espacialmente dependente, isto é, que não há autocorrelação espacial, entendida esta como a correlação entre a taxa de homicídios de uma área com a das áreas vizinhas, de um modo em que áreas com altas, médias e baixas taxas de homicídios estariam próximas de áreas também de altas, médias e baixas taxas de homicídios, respectivamente. Tal achado significa que em Betim, o homicídio se distribui aleatoriamente, diferentemente do encontrado em outros estudos realizados no distrito de Arakawa, da região metropolitana de Tókio, Japão ${ }^{15}$ e em Cascavel, no Brasil ${ }^{9}$, em ambos, a conclusão foi de que o crime, ao contrário, apresenta um padrão espacial e tende a se localizar em determinadas vizinhanças.

Se individualmente, de acordo com os resultados, tanto a taxa de homicídios como o IVS e o IQVU mostram distribuição aleatória, quando analisados conjuntamente, no entanto, eles se sobrepõem, como se observou nos mapas temáticos, indicando que maiores taxas de homicídios coincidem com áreas de vulnerabilidade social o que, de resto, é fartamente corroborado na literatura, qualquer que seja a ordem dessa vulnerabilidade, socioeconômica e cultural ${ }^{2,9,16-20}$; política ${ }^{21}$ e/ou étnico-racial ${ }^{2,22}$. De um modo ou de outro, essas vulnerabilidades, separadamente ou associadas, estão na base de explicação de diferentes abordagens sociológicas do crime.

Os fatores socioeconômicos estão entre as explicações mais comuns para a ocorrência dos crimes, e isto é feito de várias maneiras. Umas delas é localizar a origem dos homicídios nas desvantagens sociais às quais indivíduos e grupos estão submetidos, sendo essas desvantagens de natureza absoluta, isto é, pobreza, ou de natureza relativa, isto é, desigualdade e exclusão ${ }^{2}$. Em tais condições, os indivíduos e os grupos estariam muito mais susceptíveis à violência e à vitimização, não encontrando, no seu contexto e, em virtude dos parcos recursos disponíveis, formas adequadas de proteção, sejam elas do próprio indivíduo, da comunidade ou do sistema de segurança $\mathrm{a}^{9,17,22-24}$.

A propósito deste último elemento, lembramos a teoria do labeling aproach que trata o crime como resultante dos processos de criminalização seletivos provenientes das agências responsáveis pelo controle social, frente às camadas desfavorecidas e socialmente vulneráveis, articulados e perpetuados pela reação social que esses mesmos processos provocam. Assim, tal teoria, considerando a interação entre os sujeitos socialmente mais débeis, desenvolve um raciocínio de que o crime seria muito mais uma reação diante de processos de criminalização a que estão submetidos tais indivíduos, do que de uma realidade ontológica. O importante para esta teoria seria a pesquisa de que forma e por quais motivos o controle social é seletivo, atuando de modo estigmatizante sobre o indivíduo, e criando assim, diante de complexos mecanismos de interação e reação social, o fenômeno do crime e as carreiras criminosas $^{25}$.

A criminalidade, então, não deveria ser analisada somente sob a perspectiva do eventual autor de suposto fato criminoso, mas, sobretudo, sob os motivos e processos que levam os detentores do poder de atribuir determinada conduta como criminosa, de assim o procederem diante de certos indivíduos e não de outros. O objeto de estudo se desloca da conduta criminosa considerada ontologicamente, para os mecanismos de atribuição, de rotulação, de estigmatização, que 
fazem com que o sujeito perca de certa forma sua identidade social e entre no mundo do crime ${ }^{26}$.

Uma visão diferenciada, esta do labelling approach, pois parte da premissa de que a sociedade não se constitui sob valores e normas universalmente aceitos, e que supostamente o comportamento criminoso representaria uma violação a esses valores e normas, mas sim que a sociedade, em sua própria estrutura, contém dissídios, divergências, que por ser pluralista os valores variariam conforme a distribuição desigual de riquezas e poder, sendo que os processos de criminalização refletem essa desigual distribuição.

Assim, se as taxas de homicídio das regiões mais marginalizadas são maiores, isto principalmente sob a perspectiva do labeling approach, decorre destes fenômenos de criminalização que atribuem a determinadas condutas e indivíduos tal status, o que reflete na contabilização das estatísticas, ocultando outras condutas eventualmente realizadas por indivíduos provenientes de classes mais abastadas, que assim não foram rotuladas pelas agências do controle social ${ }^{26}$.

Outro modo de explicar a relação entre homicídio e precárias condições socioeconômicas é atribuir às últimas a responsabilidade pela geração de emoções negativas, que por sua vez, induziriam ao uso de droga e à entrada no crime $e^{2,6}$. A concentração de vitimização e/ou de perpetração do crime entre grupos étnico-raciais viria também explicada por fatores socioeconômicos e, antes de ser resultante de culturas violentas, estaria relacionada às desigualdades e exclusão que esses grupos sofrem ${ }^{2,12,17,20,22}$, argumento cabível no presente estudo, que tanto mostra a relação do homicídio com a vulnerabilidade social, quanto com sua distribuição racial, negros e pardos sendo responsáveis por $76,9 \%$ dos casos.

No Brasil, a relação entre homicídios e vulnerabilidade remete necessariamente à questão do tráfico de drogas e armas ${ }^{24,27,28}$, poderoso setor econômico que utiliza diferentes tipos de coerção, desde ameaças até execuções, como mecanismo de controle, coesão e fidelidade ${ }^{27}$. A associação perversa entre essa rede de atividades ilegais, a urbanização acelerada acompanhada de desenvolvimento econômico insuficiente e desigual e a pobreza resultante é responsável por grande parte dos homicídios de jovens que ocorrem no país ${ }^{27}$. Mas, adverte Zaluar, esses fatores não são suficientes para explicar a entrada no crime, aos quais, ela acrescenta, por um lado, a ineficácia do Estado no combate ao crime organizado e a sua atuação desigual focalizada nas favelas e aglomerados, apesar da articulação da rede do tráfico com setores legais e da sua conexão com interesses econômicos e políticos, ambas, ineficácia e parcialidade, gerando impunidade; por outro, a proliferação do individualismo possessivo, como princípio norteador da conduta, segundo o qual vale levantar vantagem por qualquer meio, somado à perda das práticas de integração social em virtude da mobilidade e do pouco tempo vivendo na comunidade e por fim, as próprias subjetividades de jovens que vivem nesse ambiente e que, seduzidos ou ameaçados, não têm outra escolha senão viver do tráfico e até mesmo lutar e morrer por ele ${ }^{28}$. Explicação pertinente também para os achados do presente estudo, no qual os óbitos são principalmente de jovens do sexo masculino, negros ou pardos, vivendo em aglomerados urbanos de uma cidade metropolitana, desigualmente organizada e onde se sabe prolifera o tráfico de armas e drogas.

Situações como essas oferecem argumentos para outra vertente explicativa, ainda dentro dos aspectos econômicos, aquela que se baseia em premissas da Teoria da Escolha Racional. Sendo os indivíduos racionais, suas escolhas se pautarão pela relação custo/benefício: em situação de pobreza, exclusão e falta de oportunidades por um lado, instituições de segurança pública insuficientes e pouco confiáveis, impunidade e medo, por outro, o crime pode ser mais lucrativo ou se apresentar como a melhor saída ${ }^{16,21,29,30}$. E, nessas condições, a racionalidade pode impor medidas radicais, "aqui ou se mata ou se morre" (fala de adolescente de um aglomerado urbano) ou ainda "muitas vezes, as pessoas matam, simplesmente para não serem mortas"22.

A teoria da desorganização social do crime também relaciona o crime às comunidades marcadas pelos problemas sociais, desemprego, mobilidade residencial, heterogeneidade cultural, racial e de classe social, mas o foco é outro e se refere à incapacidade, produzida por essas condições, de controle da comunidade sobre o crime, o que expõe os moradores ao conflito e produz fraqueza dos vínculos sociais, falta de aderência às normas, instabilidade, conduzindo ao crime e ao homicídio ${ }^{2,18,29}$. Essa teoria coloca a explicação do crime no ambiente, localizando-o em comunidades pobres e desorganizadas, daí sua qualidade de teoria ecológica. "A principal manifestação de desorganização social é a incapacidade de uma comunidade supervisionar e controlar seus adolescentes" 29 . Na outra ponta, situa-se o conceito de capital social, assentado nos conceitos de comunidade, redes de sociabilidade, reciprocida- 
de e solidariedade, com finalidade bem definida de promover a cooperação entre os membros e, dessa forma, a realização de objetivos individuais e de benefícios mútuos. O conceito de capital social indicaria as diferenças existentes entre as localidades e as respectivas variações da criminalidade entre elas ${ }^{15,28,29}$.

Ainda na perspectiva da relação entre crime e vulnerabilidade, a Teoria da Associação Diferencial remete a entrada no crime ao aprendizado proporcionado pelas experiências dos indivíduos em determinados ambientes, seja sofrendo ou presenciando práticas violentas, seja participando e convivendo com práticas de desrespeito às normas. Representa dessa forma, uma interação de fatores sociais e individuais, os primeiros produzindo efeitos sobre o comportamento dos segundos $^{19,29}$. A favor dessa teoria, estão as evidências de que crianças vitimizadas ou expostas a episódios violentos em casa ou na escola tendem a desenvolver ações agressivas ${ }^{31}$.

A maior vulnerabilidade de homens, relativamente às mulheres, observada no Brasil ${ }^{32}$, no mundo ${ }^{33}$ e também no presente estudo, poderia ser explicada, segundo algumas vertentes teóricas, pela maior exposição ao risco em virtude da adoção de certos estilos de vida. Assim, a maior permanência fora de casa e em hotspots, o uso pesado de álcool e de drogas ilícitas, a participação em gangues e o porte de armas de fogo, hábitos mais presentes em homens adultos e jovens, do que em crianças, velhos e mulheres, aumentariam a probabilidade de vitimização dos primeiros $^{2}$. Explicação muito diferente para o mesmo fato remete a elementos culturais relacionados tanto ao conceito de masculinidade como à sua perda, frente ao papel que as mulheres vêm assumindo atualmente, tendo por consequência a perda da visibilidade e do reconhecimento que aquele conceito conferia ao homem ${ }^{34}$.

Outra explicação nos vem dos clássicos textos de Durkheim que conceitua o crime como um ato de ofensa à consciência coletiva, sentimento forte e bem definido que exerce influência sobre os indivíduos e suas consciências, aproxima-os um dos outros, vincula-os à sociedade e produz coesão social. A essa integração social produzida por estados de consciência comuns a todos os membros, Durkheim denomina solidariedade, cuja expressão material se faz no Direito ${ }^{35}$. O crime seria normal e faria parte da vida social, primeiro porque, à moda bem típica de Durkheim, ele se encontra em todas as sociedades e essa generalização confere a ele objetividade e permite tratá-lo como um fato social. Segundo, o crime é normal em decorrência da sua própria definição: para que ele não exista numa dada sociedade, seria necessário que os estados de consciência coletiva os quais ofende fossem tão fortes que nenhuma desobediência a eles ocorresse. Mas, tal situação é impossível, porque à medida que as consciências se unificam fortemente para determinados estados e preceitos, outras situações novas, até então fracamente reguladas, surgiriam e passariam a ser passíveis de contestação. Ou seja, quando se reforça determinados estados de consciência coletiva, outros, até então mais fracos, seriam também reforçados, em relação aos quais novos crimes seriam cometidos. Mas, Durkheim vai mais longe: o crime não só é normal, como também é necessário. Se a consciência coletiva ganhasse intensidade a ponto de vincular todas as consciências, não sobraria possibilidade de mudança, logo, estaria comprometida a própria evolução da moral e do direito. É exatamente onde o crime existe que há maleabilidade suficiente da consciência coletiva para adquirir nova forma. E, além desta utilidade indireta, o crime teria ainda uma utilidade direta, que é preparar a mudança e orientar o caminho por onde a moral deve seguir "o crime antecipa a moral que está por vir"36. Normal e necessário, o crime só atinge caráter patológico quando se apresenta em números excessivos e isso ocorre quando a integração social está ameaçada ${ }^{36}$. São os estados anômicos, que ocorrem em situações de grandes mudanças, sejam crises ou mesmo grandes saltos de desenvolvimentos. Nessas situações, rompe-se a adesão das consciências individuais à sociedade, a coesão social fica comprometida e nova consciência coletiva precisará de tempo para se reorganizar. Além desses momentos agudos de distúrbios da consciência coletiva, a anomia está presente de modo crônico na indústria e no comércio, exatamente, por causa do abandono - em nome do crescimento da riqueza produzida - das regras morais e jurídicas que os regulamentavam ${ }^{35,37}$.

Finalmente, uma palavra sobre Habermas, cuja teoria articula muitos elementos apontados pelas várias teorias apresentadas e que poderia representar importante aporte para o estudo da violência.

Segundo este autor, a sociedade é constituída por mundo da vida e sistema, o primeiro sendo o âmbito do agir comunicativo; o segundo o da ação estratégica. No primeiro caso, os próprios atores envolvidos harmonizam seus planos de ação por meio da linguagem, estabelecendo assim relações de intersubjetividade e agindo dessa forma de maneira concertada no mundo. No se- 
gundo, cada ator procura atingir seu interesse, tomando os demais como variáveis a serem consideradas nos seus respectivos cálculos. No mundo da vida tem-se a integração social, isto é, a coesão social gerada pela vinculação entre sujeitos que se reconhecem reciprocamente e que constroem, nesse encontro, opinião e vontade coletiva; no sistema, tem-se controle, isto é, o efeito sobre o agregado das consequências das ações individuais, acima e fora do controle de todos. Os meios disponíveis são, para o primeiro, a solidariedade; para o segundo, o poder e o dinheiro. Mundo da vida é mundo sociocultural, que inclui esfera da vida privada e esfera pública; sistema é Estado e Economia $^{38-41}$.

O conceito de ação comunicativa envolve também a sua forma reflexiva, o discurso, forma rigorosa de comunicação que tem lugar quando, havendo questionamentos profundos nas falas dos participantes e não se podendo chegar ao entendimento, a interação é interrompida. Permanece apenas e exclusivamente a argumentação, aberta a todos e em condições de igualdade, com a garantia de que, enquanto houver discordância, a discussão persistirá e de que só valerá a força do melhor argumento. Tal processo de argumentação se inicia no aqui e agora, na prática comunicativa cotidiana, mas pode prosseguir, superar o contexto, ganhar fronteiras, abrir-se a todos os envolvidos e atingir universalidade ${ }^{42-44}$. Ação comunicativa e discurso se assentam sobre a mesma base que é o entendimento linguístico - a argumentação, que dentro do contexto gera interação; fora dele e livre dos constrangimentos da ação, constrói teorias, no caso do discurso teórico; forma racionalmente opinião e vontade coletiva, no caso do discurso prático ${ }^{38}$.

Ação comunicativa e discurso prático constituem a base da teoria de direito e democracia proposta por Habermas, tendo por ponto de partida o princípio do discurso, segundo o qual “[...] só podem reclamar validez as normas que encontrem (ou possam encontrar) o assentimento de todos os concernidos enquanto participantes de um discurso prático" e que, como princípio moral, se entrelaça ao direito ${ }^{43}$ e, dessa forma, pela institucionalização dos processos discursivos de formação da opinião e vontade coletiva, gera, de modo circular, direito legítimo e princípio da democracia $^{38}$.

Nas sociedades de capitalismo tardio, ocorre a colonização do mundo da vida pelo sistema, isto é, os processos interativos mediados pela linguagem que se desenrolam dentro do mundo da vida são substituídos pelos imperativos sistêmi- cos operados por meio do dinheiro e do poder. Dessa forma, ficam comprometidos os processos cotidianos pelos quais os atores sociais se reconhecem reciprocamente como sujeitos, dando lugar ao individualismo possessivo; os processos pelos quais produzem poder comunicativo e interferem, como cidadãos na tomada de decisão e de formulação de políticas públicas, corroendo-se assim as bases da democracia e da autonomia política, consequentemente, a conquista de direitos sociais; e, ainda, a reprodução simbólica do mundo da vida, surgindo, então, as patologias sistemicamente induzidas, a saber, perda de sentido, anomia, psicopatologias e alienações, com todas as suas consequências ${ }^{39,40,44}$. São todos processos violentos - pois transformam sujeitos em objeto - que abrem as portas para mais violência, consequentemente, para o crime.

O presente estudo traz algumas limitações. Em relação à análise geoespacial, não se pode inferir quais lugares correspondem às áreas mais ou menos violentas do município, por não haver referência ao local de ocorrência do evento e sim ao de residência da vítima ${ }^{45}$. Pode-se afirmar apenas que grande parte das vítimas atingidas por esse agravo reside em áreas socialmente mais vulneráveis. Também podem ser consideradas limitações a não inclusão de 27 UPs e a não separação dos sexos para a análise.

Viana et al. ${ }^{20}$ chamam a atenção para o cuidado ao interpretar os resultados de estudos, uma vez que existem limitações relacionadas às divisões geográficas e administrativas definidas como unidades de análise. A heterogeneidade da área urbana, onde as favelas e os bairros de classe média e alta coexistem, torna-se uma fonte potencial de distorção.

O sub-registro dos homicídios, devido às dificuldades de esclarecimento da causa básica do óbito, também pode interferir diretamente na análise dos indicadores. A insuficiência de informações na declaração de óbito sobre o local de ocorrência dos homicídios não permitiu avaliar uma possível proximidade entre a residência das vítimas e os locais de ocorrência dos homicídios.

As contribuições deste estudo, por sua vez, referem-se aos subsídios gerados para políticas públicas com ênfase nas ações preventivas, territorialmente determinadas, que ademais, poderiam ser usados como critério para repartição mais equânime dos recursos públicos, priorizando as regiões que apresentam os piores indicadores. A análise espacial, como argumenta Nahas ${ }^{11}$, é uma ferramenta útil na identificação de prioridades setoriais e demográficas para in- 
vestimentos e alocação de projetos e programas que promovam a melhoria da qualidade de vida na cidade, o que poderia contribuir para esta e a redução de mortes.

\section{Colaboradores}

R Tavares e EM Melo participaram da concepção e projeto, análise e interpretação dos dados, redação do artigo e revisão final; VDB Catalan da concepção e projeto, análise e interpretação dos dados, redação do artigo; PMM Romano da análise e interpretação dos dados, redação do artigo e revisão final. 


\section{Referências}

1. Souza ER, Melo AN, Silva JG, Franco AS, Alazraqui M, Gonzalez-Perez GJ. Estudo multicêntrico da mortalidade por homicídios em países da América Latina. Cien Saude Colet 2012; 17(12):3183-3193.

2. Lo CC, Howell JR, Cheng CT. Explaining Black-White differences in homicide victimization. Aggression and Violent Behavior 2013, 18:25-134.

3. United Nations Office on Drugs And Crime (UNODC). Global Study on Homicide Trends. Viena: UNODC; 2011.

4. Brasil. Ministério da Saúde (MS). Secretaria Executiva. DATASUS. [acessado 2015 abr 1]. Disponível em: www. datasus.gov.br

5. Gonzalez-Perez GJ, Vega-Lopez MG, Cabrera-Pivaral CE, Vega-Lopez A, Muñoz de La Torre A. Mortalidad por homicidios en México: tendencias, variaciones socio-geográficas y factores asociados. Cien Saude Colet 2012; 17(12):3195-3208.

6. Lo CC, Cheng CT. The role of social structural factors in treatment of mental health disorder. Journal of Mental Health 2012, 21(5):430-438.

7. Beato Filho CC, Assunção RM, Silva BF, Marinho FC, Reis IA, Almeida MC. Conglomerados de homicídios e o tráfico de drogas em Belo Horizonte, Minas Gerais, Brasil, de 1995 a 1999. Cad Saude Publica 2001; 17(5):1163-1171.

8. Andrade LT, Diniz AMD. A reorganização espacial dos homicídios no Brasil e a tese da interiorização. Est. bras. Est. Pop 2013; 30(Supl.):S171-S191

9. Ramão FP, Wadi YM. Espaço urbano e criminalidade violenta: análise da distribuição espacial dos homicídios no município de Cascavel/PR. Rev. Sociol. Polit. 2010; 18(35):207-230.

10. Instituto Brasileiro de Geografia e Estatística (IBGE). Censo Populacional. Rio de Janeiro: IBGE; 2010.

11. Nahas MIP, coordenador. Desenvolvimento de sistemas de indicadores sócio-ambientais (IQVU e IVS) como ferramentas de planejamento e gestão municipal da Prefeitura Municipal de Betim. Belo Horizonte: Instituto de Desenvolvimento Humano Sustentável; 2010.

12. Araujo EM, Costa MC, Oliveira NF, Santana FS, Barreto ML, Hogan V, Araújo TM. Spatial distribution of mortality by homicide and social inequalities according to race/skin color in an intra-urban Brazilian space. Rev Bras Epidemiol 2010; 13(4):549-560.

13. Moran P. Notes on continuous stochastic phenomena. Biometrika 1950; 37:17-23.

14. Neves MC, Ramos FR, Camargo ECG, Câmara G, Monteiro AM. Análise exploratória espacial de dados sócio-econômicos de São Paulo. Campinas: Embrapa Meio Ambiente, Instituto Nacional de Pesquisa Espacial; 2000.

15. Takagi D, Ikeda K, Kawachi I. Neighborhood social capital and crime victimization: Comparison of spatial regression analysis and hierarchical regression analysis. Soc Sci Med 2012; 75(10):1895-1902.

16. Berg MT, Slocum LA, Loeber R. Illegal Behavior, Neighborhood Context, and Police Reporting by Victims of Violence. Abstract Journal of Research in Crime and Delinquency 2013; 50(1):75-103.
17. Daoud N, Smulie J, Urquia M, Allan B, O'Campo P. The contribution of Socio-economic Position do Excesses of Violence and Intimate Partner Violence Among Aboriginal Versus Non-Aboriginal Women in Canadá. Can J Public Health 2013; 104(4):e278-2283.

18. Rogers ML, Pridemore WA. The effect of poverty and social protection on national homicide rates: Direct and moderating effects. Soc Sci Res 2013; 42(3):584595.

19. Jain S, Cohen AK. Behavioral Adaptation Among Youth Exposed to Community Violence: a Longitudinal ultidisciplinary Study of Family, Peer and Neighborhood-Level Protective Factors. Prev Sci 2013; 14(6): 606-617.

20. Viana LAC, Costa MCN, Paim JS, Vieira-da-Silva LM. Social inequalities and the rise in violent deaths in Salvador, Bahia State, Brazil: 2000-2006. Cad Saude Publica 2011; 27(Supl. 2):s298-s308.

21. Nóbrega Júnior JM, Zaverucha J, Rocha E. Mortes por agressão em Pernambuco e no Brasil: Um óbice para a consolidação da democracia. Rev Sociol Polit 2011; 19(40):43-58.

22. O'Flaherty B, Sethiz R. Homicide in black and white. Journal of Urban Economics 2010; 68:215-230.

23. Redelings M, Lieb Loren, Sorvillo F. Years off Your Life? The Effects of Homicide on Life Expectancy by Neighborhood and ace/Ethnicity in Los Angeles County. $J$ Urban Health 2010; 87(4):670-676.

24. Reichenheim ME, Souza ER, Moraes CL, Jorge MHPM, Silva CMFP, Minayo MCS. Violência e lesões no Brasil: efeitos, avanços alcançados e desafios futuros. Lancet 2011;377:75-89.

25. Molina AGP. Introdução aos fundamentos teóricos da criminologia. In: Molina, AGP, Gomes LF, organizadores. Criminologia: Introdução a seus fundamentos teóricos: introdução às bases criminológicas da Lei 9.099/95, Lei dos Juizados Especiais Criminais. $3^{\text {a }}$ ed. São Paulo: Revista dos Tribunais; 2000. p. 165.

26. Baratta A. Criminologia Crítica e Crítica do Direito Penal. In: Baratta A. Introdução à Sociologia do Direito Penal. $6^{a}$ ed. Rio de Janeiro: Ed. Revan, Instituto Carioca de Criminologia; 2011.

27. Zaluar A. Democratização inacabada: fracasso da segurança pública. Estud Av 2007; 21(61):31-49.

28. Zaluar A, Ribeiro APA. Teoria da Eficácia Coletiva e Violência. Novos Estudos CEBRAP 2009; 84:175-196.

29. Imura CP, Silveira AM. Como explicar a violência. In: Melo EM. Podemos Prevenir a Violência. Brasília: OPAS; 2010.

30. K'nife K, Haughton A. Social entrepreneurship: reducing crime and improving the perceptions of police performance within developing countries. International journal of Entrepreneurship 2013; 17:61-73.

31. Programa das Nações Unidas para o Desenvolvimento (PNUD). Relatório do desenvolvimento humano. New York: PNUD; 2010.

32. Waiiselfisz JJ. Mapa da violência 2012: os jovens no Brasil. São Paulo, Brasília: Instituto Sangari, Ministério da Justiça; 2012. 
33. Patton GC, Coffey C, Sawyer SM, Viner RM, Haller DM, Bose K, Vos T, Ferguson J, Mathers CD. Global patterns of mortality in young people: a systematic analysis of population health data. Lancet 2009; 374(9693):881-892.

34. Nolasco S. O apagão da masculinidade. Trabalho e Sociedade 2001; 2:9-16.

35. Durkheim E. Da Divisão Social do Trabalho. $2^{\text {a }}$ ed. São Paulo: Martins Fontes; 1999.

36. Durkheim E. As Regras do Método Metodológico. São Paulo: Abril Cultural; 1983.

37. Durkheim E. O Suicídio. São Paulo: Martins Fontes; 2000.

38. Habermas J. Between Facts and Norms, Contributions to a discourse theory of law and democracy. Cambridge: The MIT Press; 1996.

39. Habermas J. Teoria de la ación comunicativa. Madrid: Taurus; 1987.

40. Habermas J. Legitimation crisis. Boston: Beacon Press; 1975.

41. Mc Carthy T. The Critical Theory of Jurgen Habermas. 7a ed. Cambridge-London: The MIT Press; 1989.

42. Habermas J. Escritos sobre Moralidad y Eticidad. Barcelona: Paidós; 1991.

43. Habermas J. Consciência moral e agir comunicativo. Rio de Janeiro: Tempo Brasileiro; 1989.

44. Habermas J. A nova intransparência. A crise do estado de bem-estar social e esgotamento das energias utópicas. Novos Estudos CEBRAP 1987; 18:103-114.

45. Barbosa AMF, Ferreira LOC, Barros MDA. Homicídios e condição de vida: a situação na cidade do Recife, Pernambuco. Epidemiologia e Serviços de Saúde 2011; 20(Supl. 1):S19-28.

Artigo apresentado em 27/04/2015

Aprovado em 15/07/2015

Versão final apresentada em 17/07/2015 